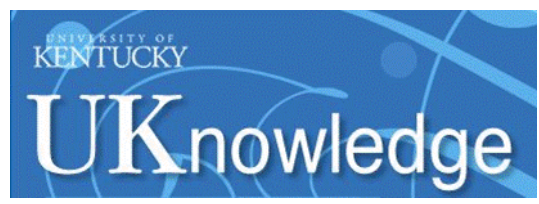

University of Kentucky

UKnowledge

\title{
Factors Leading to the Creation, Development, and Maintenance of Positive Social Relationship
}

\author{
Daniel T. L. Shek \\ University of Kentucky \\ Jocelyn L. Lin \\ Hong Kong Polytechnic University, China
}

Follow this and additional works at: https://uknowledge.uky.edu/pediatrics_facpub

Part of the Pediatrics Commons

Right click to open a feedback form in a new tab to let us know how this document benefits you.

\section{Repository Citation}

Shek, Daniel T. L. and Lin, Jocelyn L., "Factors Leading to the Creation, Development, and Maintenance of Positive Social Relationship" (2015). Pediatrics Faculty Publications. 201.

https://uknowledge.uky.edu/pediatrics_facpub/201

This Article is brought to you for free and open access by the Pediatrics at UKnowledge. It has been accepted for inclusion in Pediatrics Faculty Publications by an authorized administrator of UKnowledge. For more information, please contact UKnowledge@lsv.uky.edu. 


\section{Factors Leading to the Creation, Development, and Maintenance of Positive Social Relationship}

\section{Digital Object Identifier (DOI)}

https://doi.org/10.1515/ijdhd-2015-0454

\section{Notes/Citation Information}

Published in International Journal on Disability and Human Development, v. 14, no. 4, p. 333-342.

(C) 2015 Walter de Gruyter GmbH, Berlin/Boston

The copyright holders have granted the permission for posting the article here. 
Daniel T.L. Shek* and Jocelyn L. Lin

\section{Factors leading to the creation, development, and maintenance of positive social relationship}

DOI 10.1515/ijdhd-2015-0454

Received May 23, 2014; accepted June 19, 2014; previously published online September 12, 2015

\begin{abstract}
In contrast to the manufacturing economy where the focus is primarily placed on the man-machine interface, social relationships are important building blocks in the service economy. Hence, identifyig the factors leading to creation, development, and maintenance of positive social relationships within the context of leadership is an important consideration. In this paper, a lecture covers the nature of social relationships and the related determinants (including trust, care, and respect) are outlined. Through this lecture, students can develop the ability to identify the characteristics and determinants of positive social relationships, appreciate the importance of positive relationships to service leaders, and evaluate one's social relationships. Students are also encouraged to explore other ways to improve their social relationship qualities.
\end{abstract}

Keywords: care; respect; service leadership model; social relationships; trust.

\section{Introduction}

A social relationship refers to an association between two or more people, and it serves as the basis of social groups and society as a whole [1]. People who are involved in a relationship interact with and mutually influence one another [2]. The extent to which their feelings, thoughts,

\footnotetext{
*Corresponding author: Daniel T.L. Shek, PhD, FHKPS, BBS, SBS, JP, Associate Vice President (Undergraduate Programme) and Chair Professor of Applied Social Sciences, The Hong Kong Polytechnic University, Room HJ407, Core H, Hunghom, Hong Kong, P.R. China, E-mail: daniel.shek@polyu.edu.hk; Centre for Innovative Programmes for Adolescents and Families, The Hong Kong Polytechnic University, Hong Kong, P.R. China; Department of Social Work, East China Normal University, Shanghai, P.R. China; Kiang Wu Nursing College of Macau, Macau, P.R. China; and Division of Adolescent Medicine, Kentucky Children's Hospital, University of Kentucky, Lexington, KY, USA

Jocelyn L. Lin: Department of Applied Social Sciences, The Hong Kong Polytechnic University, Hong Kong, P.R. China
}

and behaviors are interconnected indicates the closeness of their relationship [3]. Social relationships can be built based on kinship, love, regular business interactions and social commitment, which are regulated by law, custom, or mutual agreement. Accordingly, they are categorized into family relationships, friendships and romantic relationships, which are vital to people's well-being [2], as well as other types of relationships that might be less close but also significant, such as work relationships, service provider-recipient relationships, community relationships, and leader-follower relationships.

Creation, development, and maintenance of positive social relationships are critical issues in service leadership education. First, proponents of positive psychology believe that being meaningfully connected with people is an important indicator of individual well-being [4]. The development of a strong affective relationship with and commitment to people (i.e. bonding) is highly recognized as a positive youth development construct [5]. Healthy bonding with parents, peers, and other members of the community in the life circle helps youths grow and prevents them from developing psychosocial problems $[6,7]$.

According to the Core Belief 5 of the Service Leadership and Management (SLAM) Framework [8], 'Service Leadership and Management is about creating new personal service propositions and consistently providing high quality caring service to everyone one comes into contact with, including one's self'. Hence, one can be a leader in different social contexts or relationships, providing good service in all kinds of relationships. For example, one can lead other family members out of frustration by providing emotional support in the family context. Similarly, one can lead his/her friends by providing them guidance in decision-making. Taking a leading role in building a pleasant, caring, and trustful relationship itself can be regarded as provision of service as well. With specific reference to leadership, it is important to understand the creation and management of social network, which are conducive to leadership effectiveness.

Nevertheless, in contrast to individual attributes of leaders, such as traits, skills and styles, social network or social capital of leadership is under-researched in the leadership literature [9-11]. As Brass et al. [12] noted, "little empirical work has been done on leadership and 
social networks" (p. 800). Avolio [13] echoed this limitation by proposing integrating theories of leadership and social network theories. He contended that "to the extent that leadership creates the conditions for distinct patterns of relationships between individuals in organizations to create and/or transform social network structures, there is a need to establish linkages between leadership and social network theory" (p. 31). By definition, leadership is a sort of social influence over a group of people [14]. As such, leadership development should not be constrained within the attributes of leaders themselves and should be extended to relational development [15]. In order to build positive social relationships, one should first have an idea about how and why a social relationship emerges, grows and ends, as well as why a positive social relationship is crucial to a happy, successful, and flourishing life, especially in terms of effective leadership.

\section{Relationship development and improvement}

Regarding relationship development, the most influential theory is the five-stage model (i.e. ABCDE Model) proposed by George Levinger [16]. Levinger originally proposed this model to analyze adult romantic relationships, but it has been later applied to other social relationships, such as children's relationships with their parents and peers [3]. According to this model, a relationship begins with acquaintance (A), goes through building-up (B) and continuation (C), and (alternatively) experiences deterioration (D), and finally ends (E). In the stage of acquaintance, mutual attraction makes two or more people get to know each other and decide to enter into a relationship. Initially, people who demonstrate intrinsic attributes that indicate the ability and motivation to provide emotional support, such as warmth, kindness and expressiveness, are deemed more attractive [2]. In addition, other factors also influence the likelihood of being acquainted, such as physical proximity and similarity of attributes. With the increase of self-disclosure and trust, acquaintances become closer and more interdependent to each other, which signifies the building-up stage. In this stage, two persons become increasingly sensitive to each other's needs. As the relationship continues, people in the relationship develop a lasting commitment to this relationship. On the other hand, betrayal, incompatible interests, lack of love and care, or other unresolved conflicts might make the relationship deteriorate. Deterioration will eventually lead to the end of the relationship, while other factors, such as the death of one partner, might also terminate the relationship.

A positive social relationship is beneficial to many aspects of human life, including physical health and mental health, and specifically to leadership effectiveness $[10,11,17-20]$. Although there is no consensus on what a positive social relationship looks like, and its definition varies across domains and changes with age [21], it is often assumed that a positive social relationship includes many attributes, including a sense of security, mutual trust, mutual respect, effective communication, reciprocal support, and autonomy. Positive social relationships help people gain accomplishment, go through hardship, and finally thrive. They may work through providing people with social support or a sense of social integration $[17,19,20,22]$.

Social support is defined as the provision of psychological and physical resources by social networks, which serves to enhance an individual's capacity to cope with stress [17]. A higher level of social support has been conceived as involving emotional, informational, and instrumental support [23], which results in a lower level of disease morbidity and mortality, such as lower rate of heart disease and better immune functions [20, 24, 25]. Moreover, social support also positively contributes to mental health, such as heightened self-esteem [26] and life satisfaction [27].

Mounting evidence suggests that stress-buffering accounts for the benefit of social support $[17,20]$. The stress of life events presumably elicits unhealthy behavior as a maladaptive coping strategy (e.g. smoking, excessive dieting, fewer exercises) [28], or impairs physiological symptoms of the hypothalamus-pituitary-adrenal (HPA) axis, which involves cardiovascular functions, immune functions, inflammation, and metabolic homeostasis [29]. Social support provides resources with which a person can cope with stress, thus alleviating the detrimental effect of stress on people's physical and psychological health. A meta-analysis suggested that social support has a moderate to large attenuating effect on hemodynamic reactivity induced by challenge and stress in a laboratory setting [30]. In addition, perceived availability of social support may also engender more positive appraisal of the stress situation, further reducing the occurrence of negative affect and behavior [19, 31].

Furthermore, having positive social relationships also implies enhanced social integration. Social integration refers to active participation in a broad range of social relationships, which gives rise to a sense of communality and identification with one's social roles [32]. According to Cohen's [17] main effect model of social 
integration, socially integrated people are more likely to manifest healthy behavior and reduce risk behavior due to social controls (other-regulation) or self-motivation to take care of oneself so as to fulfill one's responsibility for others. For example, social relationships can facilitate recovery from an illness by simply making patients adherent to medical treatment [33], thus improving physical and mental health [19].

In addition to physical and mental health, a positive social relationship takes a critical role in leadership effectiveness, according to social network theory of leadership [10] and leader-member exchange theory [11]. Both theories call for additional attention to the relational aspect of leadership for a more comprehensive understanding of leadership. Social network theory emphasizes the assets inherited from social network: social capital, which can be managed to obtain information, resources, opportunities, and control [34, 35]. Leaders who have extensive social capital possess more human and organizational resources that enable them to well operate their environments [10]. Effective leadership involves building and making good use of social capital $[9,15]$. Accordingly, a successful service leader should be able to accumulate useful social capital, and exploit it to serve oneself, others, and the existing systems. Furthermore, both strong ties (e.g. friendship) and weak ties (e.g. acquaintance) are important given their respective functions. Nurturing a strong and positive relationship in an organization (e.g. leader-follower relationship) creates cohesion and morale for intensive work and ensures the acquisition of credible information and solid support, while expanding diverse weak ties within and even beyond one's organization (e.g. relationship with politicians and mass media) increases access to distinctive and innovate information [10].

Another theory concerning the relational aspect of leadership is leader-member exchange theory, which emphasizes mutual trust, respect and obligation, all of which influence the parties involved (e.g. leaders and followers) [11]. People are not willing to dedicate themselves to their workplace merely owing to the authority and command of a leader. Instead, they will be more diligent in work if they have a committed relationship with their leader [36]. A growing body of evidence has suggested that high quality exchange between leaders and followers (i.e. a high degree of mutual trust, respect, and obligation) is associated with desirable leadership outcomes, such as job satisfaction, commitment, and performance of the subordinate [37].

However, social relationships may backfire in some circumstances, such as the 'dark side' of social support [38]. For example, in a study based on patients with chronic illness [39], solicitous response from the spouse fostered, rather than reduced, pain intensity among patients with a satisfying marital relationship. The authors speculated that positive attention from a significant other reinforced the expression of pain. In addition, sometimes, well-intended support may be perceived as unhelpful or upsetting, which has been found to be problematic to the mental health of the patient [40].

Researchers and practitioners have suggested numerous influential factors for initiating and maintaining positive social relationships [41, 42]. In the SLAM framework [8], it is proposed that trust, fairness, respect, care, behavioral consistency, and loyalty are of great importance to the creation, development, and sustainability of positive social relationships, leadership effectiveness, and service satisfaction. In this paper, the focus would be put on trust, care, and respect.

Trust refers to the extent to which one is willing to depend on the other party [43]. It is a basic attribute in social relationships, such as parent-child relationships [44], customer relationships [45], and leader-follower relationships [46]. Extant literature suggests that there are two categories of trust, namely, character-based trust (i.e. cognitive trust) and relationship-based trust (i.e. affective trust) $[47,48]$. The former pertains to the belief and expectation that one is trustworthy because he or she is reliable, honest, has integrity, or other character strengths. People form trust when referring to others' character strengths. The latter refers to the belief and expectation that one will demonstrate care and concern in a relationship. People form trust based on the good relationship they have experienced. This suggests that there are two pathways to enhance trust in a relationship, which can further improve the quality of a relationship. The first one is building character strengths (e.g. increasing the degree of integrity perceived by others) and the other is demonstrating care and individualized concern (e.g. increasing caring behaviors in response to the needs of others).

Trust-building in relationships is reciprocal. The mutual cyclical growth model proposed by Wieselquist et al. [49] suggests that in a close relationship, one's (A) dependence gives rise to his/her commitment in this relationship, which further elicits pro-relationship behaviors. When the partner (B) perceives these pro-relationship behaviors, he/she would enhance trust, which further increases his/her dependence. The dependence level of the partner (B) similarly elicits commitment, pro-relationship behaviors, and trust toward the former one (A). Thus, service leaders are encouraged to initiate trust in relationships, and they would be rewarded by trust and loyalty from their followers, customers, and other people having received service. 
Nonetheless, trust can become a 'poisoned chalice' if it is excessive or placed inappropriately [50]. Gargiulo and Ertug [51] challenged the dominant view on the inherent benefits of trust and pointed out the possible costs caused by over trust. Excessive trust reduces monitoring and vigilance, which increases the risk of malfeasance and other opportunistic behavior. Moreover, people in a trustful relationship are more likely to accept an outcome from such a relationship even if it is not so desirable because of emotional involvement. The first assumption was validated in Langfred's [52] study, where trust was strongly associated with diminished monitoring, and the teams with low monitoring and high individual autonomy showed poorer performance than did teams with high monitoring and high individual autonomy. Hence, it may be necessary to guide students to think critically about forming trust in a relationship.

Meanwhile, care is also crucial in a positive social relationship according to attachment theory $[53,54]$. In the early years of life, human beings develop close emotional bonds with their caregivers (primarily mothers) for the sake of survival. A secure attachment provides infants with a secure base for exploring and understanding the people in other relationships and the world. Such an attachment can transfer to other social relationships and has a long-lasting impact on human life through internal working models [55]. In a leader-follower relationship, an attachment can be built as well. According to Mayseless [56], a leader can act as an attachment figure, who serves as a secure base for followers to explore and as a safe haven for followers to heal their frustration and distress. Nurturing a secure attachment requires high sensitivity in an attachment figure to respond to the needs of the care receivers [57]. Hence, it is important for a service leader to build a secure affective bonding with the followers and to actively respond to their needs.

Respect is another important factor shaping positive relationships. Although the term 'respect' is often used in daily life, it has different interpretations in the literature. For example, Langdon [58] proposed four themes of respect based on extant literature: 1) social power (e.g. respect the people with authority), 2) social rules (e.g. respect others due to politeness), 3) caring (e.g. caring and loving are the essential features of respect), and 4) equality and acceptance of difference (e.g. respect distinct perspective of others). In the service leadership curriculum, respect is conceptualized as equality among entities and acceptance of differences, as it is more relevant to positive social relationship management while not overlapping with the concept of care. This view corresponds to the view of Lawrence-Lightfoot [59] who conceptualized respect as symmetry of relationship. She regarded respect as 'the most powerful ingredient in creating authentic relationship' [60; p. 447] and strived for promoting respect in different settings, such as education, clinics, and community. In her opinion, empowerment, healing, dialogue, curiosity, self-respect, and attention are the 'six windows' [59; p. 13] on respect.

Among these components, self-respect is closely related to service leadership, which includes provision of service to the self. Self-respect pertains to a sense of confidence and reliance on internal compass rather than external validation [60]. It is also defined as the tendency to perceive the self as the principled person deserving honor and high regard [61]. Self-respect is a prerequisite for respect toward others [60] and is beneficial for individual functioning [62]. Empirical research has indicated the benefits of self-respect to social relationships. For example, self-respect has been associated with pro-relationship behaviors in marital relationship, which further positively contributes to the well-being of the couple and the individual [61].

In conclusion, in response to the call for attention to the relational aspect of leadership development [9-11, 15], this lecture focuses on the positive social relationships in relation to service leadership. Service leadership education does not only promote the development of intrapersonal competencies or individual attributes as a leader, but also nurtures social awareness and social skills related to relationship building and management. Based on the SLAM framework, this lecture also helps students recognize 'the importance of trust, fairness, respect, care, behavioral consistency, and loyalty to the creation, development, and sustainability of positive social relationships, leadership effectiveness, and service satisfaction' [8], especially the former three components. The lecture plan is presented in the following session.

\section{Lecture content}

Few people can free themselves from social networks in the contemporary society. Positive relationships play a vital role in people's lives, contributing not only to one's mental and spiritual well-being, but also to one's physical health. For service leaders, having a positive relationship is particularly important as it allows them to successfully serve other people and develop group cohesion [10]. In this lecture, key concepts and theories about relationships are first introduced. The mechanism of relationship building, its importance, and the determinants of positive 
relationships are described, along with the relevance of positive relationships to service leadership. To deepen students' understanding about how to develop a positive relationship with others, key factors leading to positive social relationships, including trust, care and respect, are further highlighted.

It is expected that after the lecture, students are able to: a) identify the characteristics of positive/healthy relationships as well as negative/unhealthy relationships; b) appreciate the importance of positive relationships to one's personal life and service leadership; c) be aware of the process and determinants of positive relationship building; and d) evaluate one's own social relationships and explore other ways for improvement. Aside from lectures, class activities are used, including group discussion, role play, and self-reflection. The lecture plan is presented below.

\begin{tabular}{|c|c|}
\hline & Teaching content \\
\hline $\begin{array}{l}\text { Part I: What is a positive social } \\
\text { relationship? }\end{array}$ & $\begin{array}{l}\text { - Warm-up activity: “Who is in } \\
\text { your photo?" } \\
\text { - Lecture } \\
\text { - Class activity: "What } \\
\text { does a positive/healthy } \\
\text { relationship look like?" }\end{array}$ \\
\hline $\begin{array}{l}\text { Part II: The importance of a } \\
\text { positive social relationship }\end{array}$ & $\begin{array}{l}\text { - Self-reflection: "What if you } \\
\text { are alienated?" } \\
\text { - Lecture }\end{array}$ \\
\hline $\begin{array}{l}\text { Part III: How to build a positive } \\
\text { social relationship }\end{array}$ & $\begin{array}{l}\text { - Lecture } \\
\text { - Role play: “Practice makes } \\
\text { perfect” }\end{array}$ \\
\hline Part IV: Conclusion and sharing & \\
\hline
\end{tabular}

In the first part of the lecture, the basic concept of social relationships is introduced. The teacher starts the lecture by asking students to recall who are in their recently taken photos (i.e. the relationship of the student and that person). By doing this, the teacher instills in students a first impression about what a social relationship is and gives an idea that every individual can hardly live without such relationships. Then, the teacher introduces the concept of social relationships.

Next, the teacher plays two clips of music to help students understand positive and negative relationships. A group discussion follows, in which each group of students draws one kind of social relationship from a sheet (see Appendix 1), such as family relationships, friendships, and work relationships. Students pick three descriptions from the description pool provided (e.g. feel happy and satisfied, be open and trusting, be independent, vital and healthy energy; see Appendix 1) to indicate the most important features of the positive relationship they have drawn. This activity is wrapped up by highlighting that the characteristics of positive relationships are shared by different kinds of relationships and by comparing them with those of negative relationships (e.g. feel happy and satisfied vs. develop resentment and bitterness, be open and trusting vs. be closed and guarded, be independent vs. be dependent).

After the characteristics of positive social relationships are introduced, students will learn the development of social relationship based on George Levinger's fivestage model [16]. Each stage (acquaintance, building-up, continuation, deterioration, and ending) is explained using daily life examples. Students are guided to understand why some relationships continue while others deteriorate.

The second part of the lecture covers the importance of positive social relationships. At the beginning, a selfreflection exercise called 'What if you are alienated?' is conducted to help students reflect on the importance of social relationships in their lives. Students are guided to imagine what changes might happen in their lives if they are alienated from the people who are most important to them, such as their parents. Students will then report their feelings by completing a worksheet (Worksheet 1) while listening to a song that is included to stimulate their imagination. The teacher can share his/her feelings first to facilitate the activity. Feeling the pain of losing some positive social relationships makes students understand how important such a relationship is to their lives. Furthermore, the benefits of positive social relationships drawn from extant literature, which includes benefits to physical and mental health, are introduced. In particular, the teacher will elaborate why positive social relationships are important to service leadership.

Three knowledge points are highlighted in the second part of the lecture. First, a positive social relationship constitutes social capital that allows leaders successfully operating on their environments. Second, the positive relationship between leaders and followers can create cohesion and morale in the team. Third, service leaders are encouraged to build broad social networks beyond their own organization.

The third part of the lecture discusses how one can build positive social relationships. Based on the SLAM framework, service leaders need to be aware of the significance of trust, care, respect, loyalty, fairness, and behavioral consistency in the creation, development, and sustainability of positive social relationships. Accordingly, these elements can be regarded as determinants of 
positive social relationships, among which, trust, care, and respect are elaborated in this lecture.

For the issue of trust, the balance between monitoring and trust is discussed in class. Students are presented with two controversial issues about some monitoring behaviors in the parent-child relationship and leaderfollower relationship. In the former case, a Hong Kong mother monitors her daughter through an IP camera while her daughter is doing homework. In the latter case, a boss monitors his employee's performance through computer software. Students are invited to share their attitudes toward these monitoring behaviors and the impact of such monitoring on trust building. This brief discussion is followed by suggesting some appropriate and practical ways to build trust in social relationships (e.g. sharing personal information about yourself).

For the issue of care, the sensitivity and responsiveness to the needs of others are highlighted. Service leaders are able to provide secure relationships to support autonomy and free exploration of others. For the issue of respect, respecting others and respecting oneself are discussed. Regarding the former issue, equality and acceptance of differences are highly emphasized, while regarding the latter issue, accepting and appreciating oneself is highly encouraged. Finally, the mutuality of trust, care, and respect is highlighted by introducing mutual cyclical growth model of positive relationships [49]. This model focuses on trust, commitment and pro-relationship behaviors, with reciprocity of care and respect in a relationship emphasized. Students are guided to understand that one's trust, care, and respect will elicit pro-relationship behaviors toward other parties in a relationship, which further engender others' trust, care, and respect.

At the end of the third part, a class activity is conducted to provide students with an opportunity to apply the components of positive social relationships to solve relationship conflicts. First, every group draws one of the scenarios, each of which involves interpersonal conflict in one kind of social relationships (see Appendix 2). Students are required to pick one component of positive relationships (i.e. trust, care, respect, loyalty, fairness, or authenticity) and think out two ways to demonstrate how this component can solve interpersonal conflict. After group discussion, students are encouraged to demonstrate their strategies by role-playing the scenario. This activity is wrapped up by highlighting the crucial roles of these components in maintaining various social relationships.

In conclusion, the nature of social relationship and its role in service leadership are discussed in this lecture. As the relationship between positive social relationships and service leadership is not very obvious to students, the teacher should guide students to understand that building a positive social relationship (or conducting pro-relationship behaviors) is also a kind of service that a leader should provide to everyone that one comes into contact with, not simply to his/her followers. Finally, a video showing the warmth of positive social relationships is presented to promote the students' understanding of the importance of social relationships.

\section{Reflections and conclusion}

Regarding positive social relationships and service leadership, it is noteworthy that the theoretical background is mainly based on the Western literature. Actually, maintaining positive social relationship is essential to interpersonal interactions in the Chinese culture, although it is guided by collectivistic values rather than Western individualistic values [63]. In particular, emphases on harmony, 'face', and the rules of the five 'cardinal relationships' in Confucianism values (relationship between government and citizens, between parents and offspring, between husband and wife, among siblings, and among friends) are strong in the Chinese culture [64]. According to a meta-analysis on conflict resolution strategies across cultures, competing over others' interests is used as a solution for conflict more in individualistic cultures than in collectivistic cultures, whereas avoidance, compromise, and cooperation are preferred in the latter culture [65]. These findings indicate that collectivistic cultures place more other-oriented concerns on conflict resolution. Therefore, being a service leader also means being sensitive to cultural context.

Nevertheless, despite the fact that relationships are still traditionally valued in Chinese culture, the rapid changes in the past decades have possibly transformed the collectivistic to more individualistic emphases $[66,67]$. There are several challenges that might adversely affect individual social relationship building and maintenance. First, the reduced household size with fewer children per family has made more people concerned about their children's social skills development. Although there is growing evidence showing the desirable socialization of single children (vs. non-single children) $[68,69]$, it is noteworthy that there are many studies showing the relatively less favorable development of children growing in non-intact families. Second, increased mobility makes people more likely to form broad but shallow relationships rather than strong and deep ones [70]. Furthermore, Western researchers reported an ascending trend 
of narcissism in young people compared with previous generations due to increased individualism [71], and this may be also true in Chinese societies [72, 73]. Narcissistic persons tend to boost their self-esteem through public glory while overlooking one's interests, which is harmful to social relationship development. The rise in using social networking media, such as Facebook, may be associated with the growth of narcissism of young people [74]. Potential harm exists although the advancements of social media did bring about incredible benefits for human interaction, including enhancing social connectedness and well-being [75, 76]. It is also noted that amongst several Chinese societies (i.e. Hong Kong, Taiwan, and mainland China), life satisfaction is inversely

\section{Worksheet 1}

\section{What if you are alienated?}

Think about three persons who are the most important to you. associated with online communication while positively associated with face-to-face communication only in Hong Kong. Thus, simply relying on social media might not be satisfying to social life.

To conclude, positive social relationships are essential to human life, including the leadership process. While social relationships are shaped by the socio-cultural context, awareness of the dynamic influence of different factors influencing social relationships would be an advantage to service leaders.

Acknowledgments: The Service Leadership research project at The Hong Kong Polytechnic University is financially supported by the Victor and William Fung Foundation.

Write down their names/relationships with you in the left column of the table below.

Imagine if you are alienated from that person or lose your relationship with him/her, what changes might happen in your life? Write down at least one change in the right column accordingly.

\begin{tabular}{l|l}
\hline Important people & What if you lose the relationship with him/her? \\
\hline (e.g. father) & \\
\hline & \\
\hline & \\
\hline
\end{tabular}

\section{Appendix 1}

\section{What does a positive/healthy relationship look like?}

Pick three most important descriptions regarding the social relationship you picked

Social relationship:

1) Family relationship

2) Romantic relationship

3) Friendship

4) Work relationship

5) Service provider-service recipient relationship

6) Community relationship
Characteristics of positive social relationships

1) Feel your power

2) Be open and trusting

3) Experience self-confidence and security

4) Show up and take action

5) Fulfill your purpose in life

6) Lots of vital healthy energy

7) Collaborative

8) Feel happy and satisfied

9) Be independent

10) Solid self-esteem

11) Others 


\section{Appendix 2}

Practice Makes Perfect

Scenario A:
Care Trust Loyalty Authenticity Respect Fairness

Kayla lives with her mom and her stepfather, Dwayne. She and Dwayne don't always get along but she is trying to build a better relationship with him.

Pick one quality that would help Kayla and her stepfather to improve their relationship.

Think about two things that they can do to demonstrate the quality you picked and role-play the scenario.

Scenario B:

Care Trust Loyalty Authenticity Respect Fairness

Rosa and Sharon have become better friends this year. They try to do things together on the weekends, but Rosa has been pretty busy lately with the track team.

Pick one quality that would help Rosa and Sharon to improve their relationship. Think about two things that they can do to demonstrate the quality you picked and role-play the scenario.

Scenario C:

Care Trust Loyalty Authenticity Respect Fairness

Rodney and Malcolm had a fight and they both regretted. They both need to apologize before their friendship can get back on even ground.

Pick one quality that would help Rodney and Malcolm to improve their relationship.

Think about two things that they can do to demonstrate the quality you picked and role-play the scenario.

Scenario D:

Care Trust Loyalty Authenticity Respect Fairness

Sally and Tyrone have been together for six months. Most of the time, they get along really well. Sometimes, though, they argue about stupid stuff. They both want to try to communicate better and argue less often.

Pick one quality that would help Sally and Tyrone to improve their relationship.

Think about two things that they can do to demonstrate the quality you picked and role-play the scenario.

\section{References}

1. Dwyer D. Interpersonal relationships. London: Routledge, 2000.

2. Regan PC. Close relationships. New York: Routledge, 2011.

3. Levinger G, Levinger AC. The temporal course of close relationships: some thoughts about the development of children's ties. In: Hartup WW, Rubin Z, editors. Relationships and development. New York: Psychology Press, 1986:111-33.
4. Seligman ME. Flourish: a visionary new understanding of happiness and wellbeing. New York: Free Press, 2011.

5. Catalano RF, Berglund ML, Ryan JA, Lonczak HS, Hawkins JD. Positive youth development in the United States: research findings on evaluations of positive youth development programs. Ann Am Acad Polit Soc 2004;591:98-124.

6. Lee TY. Bonding as a positive youth development construct: conceptual bases and implications for curriculum development. Int J Adolesc Med Health 2006;18:483-92. 
7. Jose PE, Ryan N, Pryor J. Does social connectedness promote a greater sense of well-being in adolescence over time? J Res Adolesc 2012;22:235-51.

8. Hong Kong Institute of Service Leadership and Management. SLAM education 2013. URL: http://hki-slam.org/.

9. Balkundi P, Kilduff M. The ties that lead: a social network approach to leadership. Leadersh Quart 2006;17:419-39.

10. Brass D, Krackhardt D. The social capital of twenty-first century leaders. In: Hunt JG, Phillips RL, editors. Out-of-the-box leadership challenges for the 21st century army. Amsterdam: Elsevier, 1999:179-94.

11. Graen GB, Uhl-Bien M. Relationship-based approach to leadership: development of leader-member exchange (LMX) theory of leadership over 25 years: applying a multi-level multi-domain perspective. Leadersh Quart 1995;6:219-47.

12. Brass DJ, Galaskiewicz J, Greve HR, Tsai W. Taking stock of networks and organizations: a multilevel perspective. Acad Manage J 2004; 47:795-817.

13. Avolio BJ. Promoting more integrative strategies for leadership theory-building. Am Psychol 2007;62:25-33.

14. Yukl GA. Leadership in organization, 3rd ed. Englewood Cliffs, N): Prentice Hall, 1994.

15. Day DV. Leadership development: a review in context. Leadership Quart 2001;11:581-613.

16. Levinger G. Development and change. In: Kelley HH, Berscheid E, Christensen A, Harvey JH, Huston TL, Levinger G, et al., editors. Close relationships. New York: WH Freeman, 1983:315-59.

17. Cohen S. Social relationships and health. Am Psychol 2004;59:676-84.

18. Ertel KA, Glymour MM, Berkman LF. Social networks and health: a life course perspective integrating observational and experimental evidence. J Soc Pers Relat 2009;26:73-92.

19. Uchino BN. Social support and health: a review of physiological processes potentially underlying links to disease outcomes. J Behav Med 2006;29:377-87.

20. Thoits PA. Mechanisms linking social ties and support to physical and mental health. J Health Soc Behav 2011;52:145-61.

21. Roffey S, editor. Positive relationships: evidence based practice across the world. Dordrecht: Springer, 2012.

22. House JS, Landis KR, Umberson D. Social relationships and health. Science 1988;241:540-5.

23. House JS, Robert LK. Measures and concepts of social support. In: Cohen S, Syme SL, editors. Social support and health. San Diego, CA: Academic Press, 1985:83-108.

24. Holt-Lunstad J, Smith TB, Layton JB. Social relationships and mortality risk: a meta-analytic review. PLoS Med 2010;7:e1000316.

25. Uchino BN, Cacioppo JT, Kiecolt-Glaser JK. The relationship between social support and physiological processes: a review with emphasis on underlying mechanisms and implications for health. Psychol Bull 1996;119:488-531.

26. Williams KL, Galliher RV. Predicting depression and self-esteem from social connectedness, support, and competence. J Soc Clin Psychol 2006;25:855-74.

27. van Leeuwen C, Post MW, van Asbeck FW, van der Woude LH, de Groot S, Lindeman E. Social support and life satisfaction in spinal cord injury during and up to one year after inpatient rehabilitation. J Rehabil Med 2010;42:265-71.

28. Ng DM, Jeffery RW. Relationships between perceived stress and health behaviors in a sample of working adults. Health Psychol 2003;22:638-42.
29. Parker LN. Adrenal Gland. In: Dulbecco R, editor. Encyclopedia of human biology, vol. 1. San Diego, CA: Academic Press, 1991:71-9.

30. Thorsteinsson EB, James JE. A meta-analysis of the effects of experimental manipulations of social support during laboratory stress. Psychol Health 1999;14:869-86.

31. Schwarzer R, Knoll N. Functional roles of social support within the stress and coping process: a theoretical and empirical overview. Int J Psychol 2007;42:243-52.

32. Brissette I, Cohen S, Seeman TE. Measuring social integration and social networks. In: Cohen S, Underwood L, Gottlieb B, editors. Measuring and intervening in social support. New York: Oxford University Press, 2000:53-85.

33. DiMatteo MR. Social support and patient adherence to medical treatment: a meta-analysis. Health Psychol 2004;23:207-18.

34. Burt RS. Structural holes: the social structure of competition. Cambridge, MA: Harvard University Press, 1992.

35. Lin N. Building a network theory of social capital. Connections 1999;22:28-51.

36. Kouzes JM, Posner BZ. Credibility: how leaders gain and lose it, why people demand it. San Francisco, CA: Jossey-Bass, 2011.

37. Gerstner CR, Day DV. Meta-Analytic review of leader-member exchange theory: correlates and construct issues. J Appl Psychol 1997;82:827-44.

38. Lincoln KD. Social support, negative social interactions, and psychological well-being. Soc Serv Rev 2000;74:231-52.

39. Turk DC, Kerns RD, Rosenberg R. Effects of marital interaction on chronic pain and disability: examining the down side of social support. Rehabil Psychol 1992;37:259-74.

40. Revenson TA, Schiaffino KM, Deborah Majerovitz S, Gibofsky A. Social support as a double-edged sword: the relation of positive and problematic support to depression among rheumatoid arthritis patients. Soc Sci Med 1991;33:807-13.

41. Canary DJ, Dainton M. Maintaining relationships. In: Vangelisti A, Perlman D, editors. The Cambridge handbook of personal relationships. New York: Cambridge University Press, 2006:727-43. URL: http://www.credoreference.com/entry/ cuppr/maintaining_relationships.

42. Harvey JH, Wenzel A, editors. A clinician's guide to maintaining and enhancing close relationships. Mahwah, NJ: Lawrence Erlbaum, 2002.

43. Mayer RC, Davis JH, Schoorman FD. An integrative model of organizational trust. Acad Manage Rev 1995:20:709-34.

44. Shek DT. Perceived parent-child relational qualities and parental behavioral and psychological control in Chinese adolescents in Hong Kong. Adolescence 2006;41:563-81.

45. Swan JE, Bowers MR, Richardson LD. Customer trust in the salesperson: an integrative review and meta-analysis of the empirical literature. J Bus Res 1999;44:93-107.

46. Burke CS, Sims DE, Lazzara EH, Salas E. Trust in leadership: a multi-level review and integration. Leadersh Quart 2007;18:606-32.

47. Dirks KT, Ferrin DL. Trust in leadership: meta-analytic findings and implications for research and practice. J Appl Psychol 2002;87:611-28.

48. McAllister DJ. Affect- and cognition-based trust as foundations for interpersonal cooperation in organizations. Acad Manage J 1995;38:24-59.

49. Wieselquist J, Rusbult CE, Foster CA, Agnew CR. Commitment, prorelationship behavior, and trust in close relationships. J Pers Soc Psychol 1999;77:942-66. 
50. Skinner D, Dietz G, Weibel A. The dark side of trust: when trust becomes a 'poisoned chalice'. Organization 2014;21:206-24.

51. Gargiulo M, Ertug G. The dark side of trust. In: Bachmann R, Zaheer A, editors. Handbook of trust research. Cheltenham: Edward Elgar, 2006.

52. Langfred CW. Too much of a good thing? Negative effects of high trust and individual autonomy in self-managing teams. Acad Manage J 2004;47:385-99.

53. Bowlby J. Attachment and loss: attachment. New York: Basic Books, 1982.

54. Bowlby J. Attachment and loss: sadness and depression. New York: Basic Books, 1980.

55. Collins NL, Feeney BC. A safe haven: an attachment theory perspective on support seeking and caregiving in intimate relationships. J Pers Soc Psychol 2000;78:1053-73.

56. Mayseless 0 . Attachment and the leader-follower relationship. J Soc Pers Relat 2010;27:271-80.

57. Wolff MS, ljzendoorn MH. Sensitivity and attachment: a metaanalysis on parental antecedents of infant attachment. Child Dev 1997;68:571-91.

58. Langdon SW. Conceptualizations of respect: qualitative and quantitative evidence of four (five) themes. J Psychol 2007;141:469-84.

59. Lawrence-Lightfoot S. Respect: an exploration. Cambridge, MA Perseus Books, 2000.

60. Lawrence-Lightfoot S. Respect: on witness and justice. Am J Orthopsychiatry 2012;82:447-54.

61. Kumashiro M, Finkel EJ, Rusbult CE. Self-respect and pro-relationship behavior in marital relationships. J Pers 2002;70:1009-50.

62. Roland CE, Foxx RM. Self-respect: a neglected concept. Philos Psychol 2003;16:247-88.

63. Oyserman D, Coon HM, Kemmelmeier M. Rethinking individualism and collectivism: evaluation of theoretical assumptions and meta-analyses. Psychol Bull 2002;128:3-72.
64. Hwang KK. Foundations of Chinese psychology: Confucian social relations. New York: Springer, 2012.

65. Holt JL, DeVore CJ. Culture, gender, organizational role, and styles of conflict resolution: a meta-analysis. Int J Intercult Rel 2005;29:165-96.

66. Greenfield PM. Linking social change and developmental change: shifting pathways of human development. Dev Psychol 2009;45:401-18.

67. Kağitçibaşi Ç. Family, self, and human development across cultures: theories and applications, 2nd ed. USA: Lawrence Erlbaum Associates Publishers, 2007.

68. Mancillas A. Challenging the stereotypes about only children: a review of the literature and implications for practice. J Couns Dev 2006;84:268-75.

69. Liu RX, Lin W, Chen ZY. School performance, peer association, psychological and behavioral adjustments: a comparison between Chinese adolescents with and without siblings. J Adolescence 2010;33:411-7.

70. Oishi S, Kesebir S. Optimal social-networking strategy is a function of socioeconomic conditions. Psychol Sci 2012;23:1542-48.

71. Twenge JM. The evidence for generation me and against generation we. Emerg Adulthood 2013;1:11-6.

72. Cai H, Kwan VS, Sedikides C. A sociocultural approach to narcissism: the case of modern China. Eur J Personality 2012;26: 529-35.

73. Shek DT, Wong KK. Do adolescent developmental issues disappear overnight? Reflections about holistic development in university students. ScientificWorldJournal 2011;11:353-61.

74. Twenge JM. Does online social media lead to social connection or social disconnection? J Coll Character 2013;14:11-20.

75. Valkenburg PM, Peter J. Social consequences of the internet for adolescents a decade of research. Curr Dir Psychol Sci 2009;18:1-5.

76. Valkenburg PM, Peter J. Online communication and adolescent well-being: testing the stimulation versus the displacement hypothesis. J Comput-Mediat Comm 2007;12:1169-82. 